Original Article

\title{
The effect of chiropractic techniques on the Cobb angle in idiopathic scoliosis arising in adolescence
}

\author{
Sunghak Byun, PhD ${ }^{1)}$, Dongwook Han, PhD, $\left.\mathrm{PT}^{2}\right)^{*}$ \\ 1) Good Posture Association, Republic of Korea \\ 2) Department of Physical Therapy, College of Health and Welfare, Silla University: 700 beon-gil, 140 \\ Baegyang-daero, Sasang-gu, Busan 617-736, Republic of Korea
}

\begin{abstract}
Purpose] The purpose of this study was to examine whether chiropractic techniques would reduce the curvature of idiopathic scoliosis, which commonly occurs in elementary school children. [Subjects] The subjects of this study were 5 healthy elementary students who listened to an explanation of the study methods and purpose of the study and agreed to participate in the experiment. [Methods] The Cobb angle was measured by taking an X-ray (FCT-1, Dongmun, Goyangsi, Republic of Korea) taken from the rear, using X-ray film. The method of intervention this study used was application of chiropractic techniques. Spinal correction was carried out for 30 minutes per session, which included soft tissue massage, 3 times a week for 8 weeks. [Results] It was established that the Cobb angle was noticeably decreased after 4 weeks of the intervention. Post Hoc analysis revealed that the Cobb angle noticeably decreased after 4 weeks compared with the Cobb angle before the chiropractic techniques were applied. However, no significant difference in Cobb angle was evident after the fourth week. [Conclusion] This study demonstrated that chiropractic techniques can effectively reduce the Cobb angle within as little as 4 weeks. So, we can confirm that the chiropractic techniques were effective for reducing the curvature of idiopathic scoliosis.

Key words: Scoliosis, Cobb angle, Chiropractic technique
\end{abstract}

(This article was submitted Nov. 24, 2015, and was accepted Dec. 18, 2015)

\section{INTRODUCTION}

Most students today have many posture-related health problems due to academic stress and habits that cause inadequate posture, i.e, using a computer for long hours, incongruent height of a desk and a chair, heavy backpacks, and lack of exercise $^{1)}$. In particular, even when there is no clear cause, it is easy for spinal deformity to occur in adolescence, and once spinal deformity begins, the spinal curvature consistently becomes more severe. Therefore, it may develop into scoliosis. The word scoliosis was first used by Galen (AD 131-201), and it referred to one or more vertebrae slanting sideways and therefore exhibiting lateral declination and rotation ${ }^{2}$. Currently, a Cobb angle above $10^{\circ}$ is defined as scoliosis ${ }^{3)}$, and in children, idiopathic scoliosis of unknown cause occurs quite commonly ${ }^{4}$. According to domestic and foreign reports, researchers have come up with different results, but it is commonly known that the prevalence rate of scoliosis is about $0.3 \%$ to $21.0 \%{ }^{5}$. Idiopathic scoliosis occurs slowly and gradually, hence it is hard for the parents and children themselves to discover it until it fully develops into scoliosis ${ }^{6}$. Complications that arise secondarily are malfunction ${ }^{7}$, fatigue and pain ${ }^{8)}$, neurological complications, problems with appearance ${ }^{9)}$, psychological problems ${ }^{10)}$, and shortening of life expectancy ${ }^{11)}$. Because of the many of health problems that appear as scoliosis advances, awareness of the need for early diagnosis of scoliosis and early conservative treatment is increasing. In particular, one report demonstrated that early discovery and treatment, and sometimes surgical intervention, are effective in managing scoliosis ${ }^{12}$. In 1981, it was discovered in Sweden that early examination and early treatment can reduce the progress of scoliosis from $40 \%$ to $63 \%{ }^{13)}$. In 15 of the 50 states of the United States, screening for scoliosis in school is required by law. The American Academy of Orthopedic Surgeons recommends that female students

*Corresponding author. Dongwook Han (E-mail: dwhan@silla.ac.kr)

(C)2016 The Society of Physical Therapy Science. Published by IPEC Inc.

This is an open-access article distributed under the terms of the Creative Commons Attribution Non-Commercial No Derivatives (by-nc-nd) License $<$ http://creativecommons.org/licenses/by-nc-nd/4.0/>. 
should be screened twice between the ages of 11 and 13 and that male students should be screened once between the ages of 13 and $14^{14)}$.

Both conservative and surgical treatments for scoliosis are available. Conservative treatments include treatment using physical parameters, exercise treatment, physiotherapy including degree revisal, and a support device that is used to restrain scoliosis from progressing further ${ }^{15}$. Many studies have been undertaken on exercises that can control the imbalance of muscles around the spine. Studies on the effect of exercise treatments, such as the effect of early exercise treatment on idiopathic scoliosis occurring in elementary school students ${ }^{16}$, the effect of core muscle relaxation technique on the Cobb angle in scoliosis ${ }^{17)}$, the effect of Swiss ball exercise on respiratory function and trunk regulation ability of scoliosis patients ${ }^{18)}$, and the effect of height exercise, Schroth exercise, and other strengthening exercises on scoliosis ${ }^{19}$, have been undertaken. However, studies on the effect of spine correction, which falls in the category of conservative treatments, are lacking. A few studies, such studies of the effect of body correction on structural scoliosis ${ }^{20}$, the effect of body correction on the Cobb angle of high school female students with scoliosis ${ }^{21}$, the effect of scoliosis angle on center of gravity sway ${ }^{22}$, and the good way to assess scoliosis ${ }^{23}$, 24), have been performed. However, these studies are few in number in comparison with the studies on the effects of exercise treatment on scoliosis.

Therefore, this study examined whether chiropractic techniques applied to elementary school children who were confirmed to be suffering from idiopathic scoliosis would reduce the spinal curvature at an early stage.

\section{SUBJECTS AND METHODS}

In order to select participants for this study, a forward bending test was carried out on training students at a Taekwondo gym of H-gu, Busan, Republic of Korea. Out of 20 students that showed a positive result from the test, 12 students understood the purpose and aim of this study and voluntarily wanted to participate. This study complied with the ethical standards of the Declaration of Helsinki, and written informed consent was received from each participant. After receiving written informed consent, a radiograph was taken on the following day. Five students with a Cobb angle above $10^{\circ}$ were selected as final study participants. Table 1 shows the results of analysis on general characteristics of study participants ${ }^{25)}$. The average age of the study participants was 11.8 , the average height as $144.4 \mathrm{~cm}$, and the average weight was $40.4 \mathrm{~kg}$. The average Cobb angle before the intervention was $11.2^{\circ}$ (Table 1 ).

The Cobb angle was measured by taking an X-ray (FCT-1, Dongmun, Goyangsi, Republic of Korea) from the rear, using $\mathrm{X}$-ray film. Lines were drawn on the film connecting the upper spine at the top of the concave part of the curvature with the lower spine at the bottom of the curvature, and then a perpendicular line was drawn from each line, and the angle where the perpendicular lines intersected was the Cobb angle ${ }^{26}$.

The method of intervention this study used was application of chiropractic techniques. In application of chiropractic techniques, the part of the spine that does not maintain correct alignment is identified, and the spine is adjusted with force to achieve proper alignment. Sudden, momentary pressure is administered against the spinal area, and if muscles around the spine are tense, there is a possibility of muscle damage, so it is necessary to relax soft tissues around the vertebrae before applying chiropractic techniques. For this reason, a soft tissue massage was given to the subjects prior to chiropractic treatment. The chiropractic techniques used in this study were correction techniques for the iliac and mammillary processes of lumbar vertebrae, which are pelvic and lumbar correction methods. Thoracic vertebral correction techniques for the transverse processes of thoracic vertebrae were performed utilizing the therapist's hands. Furthermore, the correction techniques for the transverse processes of the atlas and articular processes of the cervical vertebrae, which are cervical vertebra correction methods, were used ${ }^{27}$. Spine correction was carried out for 30 minutes per session including soft tissue massage, 3 times a week for 8 weeks ${ }^{25)}$.

Normality of the data for 5 study participants was tested and verified by Shapiro-Wilk test. In order to quantify the decrease in Cobb angle after 4 weeks and again after 8 weeks compared with the Cobb angle before the intervention, repeated measures ANOVA tests were performed. The statistical program used for this study was IBM SPSS Statistics for Windows (ver. 21.0), and the significance level used was set as $\alpha=0.05$.

Table 1. Characteristics of the subjects $(n=5)$

\begin{tabular}{lcccc}
\hline Subjects & Age (years) & Height $(\mathrm{cm})$ & Weight $(\mathrm{kg})$ & Cobb angle \\
\hline $1(\mathrm{M})$ & 13 & 155 & 47 & $10^{\circ}$ \\
$2(\mathrm{M})$ & 13 & 158 & 48 & $10^{\circ}$ \\
$3(\mathrm{M})$ & 12 & 137 & 35 & $13^{\circ}$ \\
$4(\mathrm{M})$ & 10 & 138 & 40 & $11^{\circ}$ \\
$5(\mathrm{~F})$ & 11 & 134 & 32 & $12^{\circ}$ \\
Mean \pm SD & $11.8 \pm 1.3$ & $169.8 \pm 2.1$ & $67.7 \pm 7.8$ & $11.2 \pm 1.3$ \\
\hline
\end{tabular}

F: female; M: male 


\section{RESULTS}

Table 2 shows the results regarding the changes in Cobb angle in each participant. In male 1 , the Cobb angle was $10^{\circ}$ before the intervention, $0^{\circ}$ after intervention for 4 weeks, and $0^{\circ}$ after intervention for 8 weeks. Male 2 had a Cobb angle of $10^{\circ}$ before the intervention, $0^{\circ}$ after intervention for 4 weeks, and $0^{\circ}$ after intervention for 8 weeks. In male 3 , the Cobb angle was $13^{\circ}$ before the intervention, $7^{\circ}$ after intervention for 4 weeks, and $0^{\circ}$ after intervention for 8 weeks. In male 4 , the Cobb angle was $11^{\circ}$ before the intervention, $5^{\circ}$ after intervention for 4 weeks, and $5^{\circ}$ after intervention for 8 weeks. In female 1 , the Cobb angle was $12^{\circ}$ before the intervention, $0^{\circ}$ after intervention for 4 weeks, and $0^{\circ}$ after intervention for 8 weeks (Table 2).

As a result of identifying statistically significant differences in the above results, it was determined that the Cobb angle had noticeably decreased after 4 weeks and 8 weeks. Post Hoc analysis with the Bonferroni test showed that the Cobb angle noticeably decreased after 4 weeks compared with the Cobb angle before applying chiropractic techniques, but there was no significant difference in Cobb angle after 4 weeks or 8 weeks. Therefore it was demonstrated that chiropractic techniques can effectively reduce the Cobb angle within as little as 4 weeks (Table 3 ).

\section{DISCUSSION}

Although scoliosis has various causes, once it occurs, it consistently progresses and leads to changes in the level of tension in muscles around the spine. If this kind of change is allowed to continue, the muscles on either side of the spine do not develop in balance, and this causes muscles on one side to shorten abnormally and muscles on the other side to stretch abnormally, hence causing the spine to displace in one direction, causing curvature of the spine. Thus, the main body of the spine getting displaced in one direction rotates, exacerbating the curvature further to the point that it becomes visible. Scoliosis results in spine displacement sagittally, spine centrifugal distortion horizontally, and an abnormal curvature. All of these things cause pain, restrictions to spinal movement, and degeneration. Regarding this matter, McMorland and Suter ${ }^{28)}$ stated that abnormal stresses arise around the affected joints when vertebrae are displaced and that the pain and restrictions to range of motion consequentially occur. Park ${ }^{29}$ reported that as a result of identifying the relationship between spinal instability, vertebral displacement and vertebral degeneration, spinal instability, vertebral displacement, and increased arthritis were demonstrated to be associated with scoliosis of the spine. Since scoliosis causes pain and motion restriction, thereby deteriorating the quality of life, it is important to discover and treat it at an early stage.

The general principles of scoliosis treatment include correction of transformed spine curvature, and strengthening of related soft tissues. Hence in order to treat scoliosis, it is necessary to adjust spinal rotation, push the spine towards the opposite direction of its abnormal bending to align the vertebrae correctly, and balance the muscles around the spine that have developed asymmetrically.

Lee $^{14)}$ stated that exercises for strengthening muscles around the spine were effective in prevention and treatment of scoliosis. Choi ${ }^{16)}$ reported that as a result of implementing exercises to cure elementary school students with idiopathic scoliosis in the early stages, the Cobb angle decreased. Cho and Jang ${ }^{30)}$ reported that as a result of applying an exercise program to strengthen the trunk and extremity muscles in adolescents, the Cobb angle improved along with improvement of muscular strength and muscular endurance. These kinds of results imply that if the balance of muscles on either side of the

Table 2. The changes in Cobb angle in each subject (Unit: degrees)

\begin{tabular}{cccc}
\hline Subjects* & Before intervention & After 4 weeks & After 8 weeks \\
\hline $1(\mathrm{M})$ & 10 & 0 & 0 \\
$2(\mathrm{M})$ & 10 & 0 & 0 \\
$3(\mathrm{M})$ & 13 & 7 & 0 \\
$4(\mathrm{M})$ & 11 & 5 & 5 \\
$5(\mathrm{~F})$ & 12 & 0 & 0 \\
Mean \pm SD & $11.2 \pm 1.3$ & $2.4 \pm 3.4$ & $1.0 \pm 2.2$ \\
\hline
\end{tabular}

F: female; M: male *Adapted from Byeon, 2008

Table 3. The changes in Cobb angle after 4 and 8 weeks of the intervention (Unit: degrees)

\begin{tabular}{lrcc}
\hline Variables & Before intervention & After 4 weeks & After 8 weeks \\
\hline Cobb angle $* *$ & $11.2 \pm 1.3^{\mathrm{a}}$ & $2.4 \pm 3.4 \dagger$ & $1.0 \pm 2.2 \ddagger$ \\
\hline${ }^{\mathrm{a}}$ Mean $\pm \mathrm{SD}^{* *} \mathrm{p}<0.01$ & & \\
$\dagger$ Before intervention $>$ After 4 weeks & & \\
&
\end{tabular}


spine is fixed through muscle strengthening exercises, scoliosis could be improved.

However, when the level of scoliosis is moderate or severe, the benefits of exercise ${ }^{31)}$ are limited. For that reason, interest in degree correction methods as methods of scoliosis treatment to correct vertebral alignment is increasing. Park et al. ${ }^{21)}$ reported that as a result of implementing manipulative therapy combining the Gonstead technique and Cox technique in female high school students with scoliosis, the Cobb angle improved. Romano and Negrini ${ }^{32)}$ reported that as a result of systematic review, chiropractic techniques, and manipulation, positive effects on reduction of the angle in scoliosis were achieved. In application of chiropractic techniques, a specific area of the vertebrae and joint is identified, and a rapid, low-amplitude stimulus is applied to correct the joint by applying force to it so that the joint moves into the physiological range and past the elastic range, which is the normal motion range of the joint ${ }^{33)}$. Therefore, chiropractic techniques are known to correct a twisted spine, restore muscle imbalance, help restore functions of spinal nerves ${ }^{34)}$, and stimulate the Golgi tendon organ located around tendons to relax muscle and expand motion range ${ }^{35)}$. However, even though chiropractic techniques have a positive effect on spine correction, studies on the effect of chiropractic techniques in the correction of scoliosis in growing adolescents are lacking. Hence, this study aimed to identify the effect of chiropractic techniques on scoliosis in elementary school students. The results showed that the spinal curvature in the subjects was reduced significantly in 4 weeks, although there was no significant difference between 4 weeks and 8 weeks. These results imply that chiropractic techniques performed on children with idiopathic scoliosis can achieve a near-normal spinal alignment within 4 weeks. On the other hand, since the number of study participants was small, this study is too limited in scope to be able to predict results in a larger population. Therefore, a study that applies chiropractic techniques to a larger number of participants and observes and records the effects should be performed. Nevertheless, the results of this study imply that in clinical practice, a direct correction to the spine is necessary for treating scoliosis. Hence spinal correction should be included as a part of the program for treatment of scoliosis.

\section{ACKNOWLEDGEMENT}

The data, subjects, and methods in this study were based on the master's thesis of Sung-Hak, Byeon in 2008.

\section{REFERENCES}

1) Chae HW, Shin YG, Lee SC, et al.: A study on the posture of Korean students. Stud Phys Educ Sci, 1990, 6: 55-166.

2) Lonstein JE, Bradford DS, Winter RB, et al.: Moe's Textbook of scoliosis and other spinal deformities, 3rd ed. Philadelphia: W.B. Saunders Company, 1995.

3) Bunnell WP: The natural history of idiopathic scoliosis before skeletal maturity. Spine, 1986, 11: 773-776. [Medline] [CrossRef]

4) McCarthy RE, McCullough FL: Shilla growth guidance for early-onset scoliosis: results after a minimum of five years of follow-up. J Bone Joint Surg Am, 2015, 97: 1578-1584. [Medline] [CrossRef]

5) Kim BY, Park JH, Kim PT: Cross-sectional survey for prevalence rate of scoliosis in primary, middle and high school boys in Pusan city. J Prev Med Pub Health, 1988, 21: 217-223.

6) Kane WJ, Brown JC, Hensinger RN, et al.: Scoliosis and school screening for spinal deformity. Am Fam Physician, 1978, 17: 123-127. [Medline]

7) DiRocco PJ, Vaccaro P: Cardiopulmonary functioning in adolescent patients with mild idiopathic scoliosis. Arch Phys Med Rehabil, 1988, 69: 198-201. [Medline]

8) Ramirez N, Johnston CE, Browne RH: The prevalence of back pain in children who have idiopathic scoliosis. J Bone Joint Surg Am, 1997, 79: 364-368. [Medline]

9) Radl R, Maafe M, Ziegler S: [Scoliosis: the bent spine]. Orthopade, 2011, 40: 449-462. [Medline] [CrossRef]

10) Payne WK 3rd, Ogilvie JW, Resnick MD, et al.: Does scoliosis have a psychological impact and does gender make a difference? Spine, 1997, 22: 1380-1384. [Medline] [CrossRef]

11) Klimo P Jr, Rao G, Brockmeyer D: Congenital anomalies of the cervical spine. Neurosurg Clin N Am, 2007, 18: 463-478. [Medline] [CrossRef]

12) Suh SW, Modi HN, Yang JH, et al.: Idiopathic scoliosis in Korean schoolchildren: a prospective screening study of over 1 million children. Eur Spine J, 2011, 20: 1087-1094. [Medline] [CrossRef]

13) Oda M, Rauh S, Gregory PB, et al.: The significance of roentgenographic measurement in scoliosis. J Pediatr Orthop, 1982, 2: 378-382. [Medline] [CrossRef]

14) Lee SH: A Study on the actual conditions of scoliosis in fifth and sixth grade school children. J Korean Soc Sch Health, 
1999, 12: 143-148.

15) Weiss HR, Negrini S, Rigo M, et al. (SOSORT guideline committee): Indications for conservative management of scoliosis (guidelines). Scoliosis, 2006, 1: 5. [Medline] [CrossRef]

16) Choi HS: The effect of the early therapeutic exercsie on idiopathic scoliosis in elementary school children in Seosan city. Kei Myung University, Dissertation of doctorate degree, 1999.

17) Lee MG, Hwang JS, Seo BD, et al.: The effects of the core muscle release technique on scoliosis. J Phys Ther Sci, 2013, 25: 445-448. [CrossRef]

18) Kim JJ, Song GB, Park EC: Effects of Swiss ball exercise and resistance exercise on respiratory function and trunk control ability in patients with scoliosis. J Phys Ther Sci, 2015, 27: 1775-1778. [Medline] [CrossRef]

19) Yang JM, Lee JH, Lee DH: Effects of consecutive application of stretching, Schroth, and strengthening exercises on Cobb's angle and the rib hump in an adult with idiopathic scoliosis. J Phys Ther Sci, 2015, 27: 2667-2669. [Medline] [CrossRef]

20) No YH: Clinical study on Cox technique which is a remedial treatment for structural scoliosis. Academic Journal of the Society of Korean Medicine Rehabilitation, 1998, 8: 72-85.

21) Prak GD, Ju SB, Yun SD: The effect of chiropractic on ROM of spine and balance of dynamic for scoliosis patients. Korean J Phys Sci Educ, 2006, 15: 561-570.

22) Park JY, Park GD, Lee SG, et al.: The effect of scoliosis angle on center of gravity sway. J Phys Ther Sci, 2013, 25: 1629-1631. [Medline] [CrossRef]

23) Lim JH, Lee J, Koh SE, et al.: Reliability and reproducibility of interapical distance assessment of the lateral deviation of vertebrae in scoliosis. J Phys Ther Sci, 2015, 27: 1199-1202. [Medline] [CrossRef]

24) Linek P, Saulicz E, Wolny T, et al.: Ultrasound evaluation of the symmetry of abdominal muscles in mild adolescent idiopathic scoliosis. J Phys Ther Sci, 2015, 27: 465-468. [Medline] [CrossRef]

25) Byeon SH: An effect of chiropractic and massage on scoliotics' Cobb's angle and sense of equilibrium. Busan University of Foreign Studies, Master's thesis, 2008.

26) Kim H, Kim HS, Moon ES, et al.: Scoliosis imaging: what radiologists should know. Radiographics, 2010, 30: 18231842. [Medline] [CrossRef]

27) SuZuKi SIK: Outline of Chiropractic. Seoul: Jungdam, 2005.

28) McMorland G, Suter E: Chiropractic management of mechanical neck and low-back pain: a retrospective, outcomebased analysis. J Manipulative Physiol Ther, 2000, 23: 307-311. [Medline]

29) Park JC: Perifacetal soft tissue enhancement on MR imaging of the lumbar spine: significance and relation to sagittal instability. Catholic University of Daegu, Master's thesis, 2010.

30) Cho HJ, Jang MJ: Effect of the Thera-band exercise to idiopathic scoliosis of juveniles. Korean J Growth Dev, 2011, 19: $31-36$.

31) Kisner C, Colby LA: Therapeutic exercise: foundations and techniques, 5th ed. F.A. Davis Company, 2007.

32) Romano M, Negrini S: Manual therapy as a conservative treatment for adolescent idiopathic scoliosis: a systematic review. Scoliosis, 2008, 3: 2. [Medline] [CrossRef]

33) Shekelle PG: Spinal manipulation. Spine, 1994, 19: 858-861. [Medline] [CrossRef]

34) Coulter ID, Hurwitz EL, Adams AH, et al.: Patients using chiropractors in North America: who are they, and why are they in chiropractic care? Spine, 2002, 27: 291-296, discussion 297-298. [Medline] [CrossRef]

35) Colloca CJ, Keller TS: Stiffness and neuromuscular reflex response of the human spine to posteroanterior manipulative thrusts in patients with low back pain. J Manipulative Physiol Ther, 2001, 24: 489-500. [Medline] [CrossRef] 